535 RISING INFANT MORTALITY IN AN AREA OF hIGH ACCESS TO NEONATAL INTENSIVE CARE. L.R. F1rst, P.H. W1se, H. Hersee, J. Rideout, B. Boardman, G.A. Lamb. (Spon. by J.B. Richmond). Harvard Medical School, Boston University Medical School, Children's Hospital, Boston City Hospital, Boston.

Reports from several citles have suggested recent increases in infant mortality (IM). We studied recent trends in Boston, a city where $93 \%$ of infants are born in centers with Leve1 III neonata1 intensive care. Linked birth/death vital statistics files were analyzed, and infant and maternal medical records for all resident infants who died from 1980 through 1983 were reviewed. The data suggest a plateauing in the survival of low birth welght (LBW) infants and recent increases in high birth weight (HBW) and postneonatal mortallty. These increases were related to conditions generally associated with poor access to medical care. Birthweight distributive effects were minimal over this time period.

TRENDS IN BIRTH WEIGHT-SPECIFIC, POSTNEONATAL, AND TOTAL IM

$\begin{array}{lrrrr} & 1969-71 & 1977-79 & 1980-81 & 1982-83 \\ \text { LBW }(\leq 2500 \mathrm{~g}) & 138.0 & 108.0 & 76.3 & 83.1^{*} \\ \text { HBW }(>2500 \mathrm{~g}) & 3.7 & 1.2 & 1.1 & 2.7^{*} \\ \text { POSTNEONATAL } & 5.1 & 3.7 & 3.1 & 35^{*} \\ \text { INFANT } & 21.2 & 16.4 & 12.4 & 13.8^{*}\end{array}$

(rates per 1000 livebirths) * $\mathrm{p}<0.01$. These data suggest that in populations with longstanding access to high quality neonatal intensive care, annual incremental
improvements in LBW survival may become minimal. In this setting observed increases in $\mathrm{HBW}$ and postneonatal mortality may cause overall infant mortality rates to rise.

\section{EPFECT OF APGAR SCORE ON SURVIVAL OF THE} VLBW INFANT. David E. Fisher, John B. Paton, Stephen A. Myers, Pritzker Sch. of Med., Univ. of
Depts. Peds. and OB/Gyn, Chicago, nll.

Reese Hosp., Depts. Peds. and $\mathrm{OB} /$ Gyn, Chicago, Ill. To plan appropriate obstetric and pediatric intervention for
a r pregnancies resulting in VLBW infants, the physician needs to be
informed of outcome data at the delivering institution. We reviewed informed of outcome data at the delivering institution. We reviewed
9552 live births from Jan ' 82 through Aug ' 84 when our crude neonatal 9552 live births from Jan ' 82 through Aug ' 84 when our crude neonatal
mortality rate was 15.5 and our VLBW rate was $3.8 \%$. Because of rapidly improving outlook for VLBW infants, $B W$ and GA specific mortality analysis by $100 \mathrm{~g}$ inerements or 1 week $\mathrm{GA}$ intervals is
essential. Of 137 neonates 1007 weighing $600-1499 \mathrm{~g}$, with Apgar score of 4 or more, the survival was $93 \%$. For 190 neonates between 23 \& 32 weeks $G A$, with $1 \mathrm{~min}$. Apgar score of 4 with 1 min. Apgar score of
or more, survival was $94 \%$. or more, survival was $94 \%$. When the 1 min Apgar score
was 3 or less, survival was $51 \%$ was 3 or less, survival was $51 \%$ and $57 \%$ for comparable $B W$ of pregnancy is the most important factor to improve outcome for the VLBW infant; when this is not possible when this is not possible assuring optimal condition at
birth becomes the highest priority.

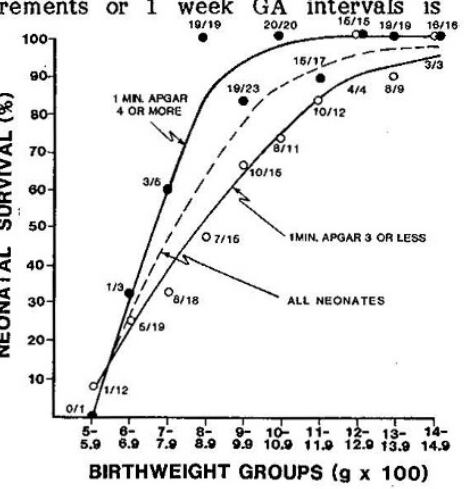

AEROBIC EXERCISE AND ATHEROSCLEROTIC RISK FACTORS IN $† 537$ ADOLESCENTS. Raymond R. Fripp; Robert Winter, James llodgson, Peter 0 . Kwiterovich, Victor Whitman, H. Gregg Schuler. The Pennsylvania State University College of Medicine, The Milton s.
Pediatrics, Hershey, PA

The effect of a 7 week aerobic exercise program on atherosclerotic risk factors was assessed in 65 adolescent white males (mean age $15.8 \mathrm{yrs}$ ). Each subject was evaluated before and (mean age $15.8 \mathrm{yrs}$ ). Each subject was evaluated before and $\mathrm{ht}^{2}$ ), \% fat, systolic and diastolic blood pressure, maximum oxygen consumption ( $\mathrm{MV}_{2} \mathrm{O}_{2}$, exercise duration (ED) and fasting plasma lipids (cholesterol (CHL), triglyceride (TGL), high density lipoprotein (HDL-C) and low density lipoprotein (LDL-C)). Mean weight $( \pm$ SD) was $70.7 \pm 16.5 \mathrm{~kg}$ before and $71 \pm 16.5$ after training (p NS). BMI was $23.2 \pm 4.6$ and $23.2 \pm 4.7$ (p NS). \% fat decreased by $7.9 \%$ from $20.3 \pm 6.9$ to $18.7 \pm 6.3 \%(\mathrm{p}<0.001)$. Systolic and diastolic blood pressure remained unchanged, $\mathrm{MVO}_{2}$ increased by $10.8 \%$ from $45 \pm 6.5$ to $49.9 \pm 7.8 \mathrm{ml} / \mathrm{kg} \cdot \mathrm{min}^{-1}$ (p < 0.0001 ) and ED increased from $20.5 \pm 2.6$ to $21.1 \pm 2.5 \mathrm{~min}(\mathrm{p}<$ 0.01 ). Plasma lipids (mg/d1) were similar pre and post exerciseCHL $154 \pm 32$ and $152 \pm 31$, TGL $87 \pm 46$ and $92 \pm 40$, HDL-C $46 \pm 12$ and $45 \pm 9$ and LDL-C $90 \pm 21$ and $88 \pm 27$. These results demonstrate that with the exception of obesity, atherosclerotic risk factors are not modified by an effective aerobic training program in adolescent males. This is at variance from that reported in adults undergoing aerobic training.
+538 AN OUTBREAK OF PSEUDOBACTEREMIA CAUSED BY EWINGELLA AMERICANA. Sherry Gardner, Kathy Kabat, and StanUniversity Mord. Schoo1, Children's Mem. Hosp., Chicago.

Between September, 1981, and Apri1, 1984, Ewingella americana was recovered from blood cultures from 21 patients in the intensive care units and emergency room of a 265 -bed pediatric hospital. Because clinical presentations were generally not suggestive of Gram-negative bacteremia, we began an epidemiologic in vestigation for a source of pseudobacteremia. $E$. americana is a new genus and species in the family Enterobacteriaceae, previous1y known as CDC enteric group 40 . It has been reported as a pathogen only once. A case-control study showed that cases were much more 1ikely than controls to have had blood obtained for coagulation profiles with cultures ( $15 / 19$ vs. $4 / 39$ controls, $p=$ agulation profiles with cultures $(15 / 19$ vs. $4 / 39$ controls, $\mathrm{p}=$
$\left.3.4 \times 10^{-7}\right)$. Coagulation tubes had been prepared with crystalline sodium citrate and citric acid in distilled deionized water. Blood for both coagulation studies and culture was occasionally instilled into the screw-top coagulation tube before blood culture bottles were inoculated. We hypothesized that if the citrate solution were contaminated, the needle or syringe hub could have transferred $E$. camericana to the blood culture bottles, resulting in false positives. $E$. cmericana was recovered from all of 80 unused coagulation tubes and from no other environmental sources. Personnel obtaining blood for multiple studies should adhere to strict aseptic technique. Laboratories should consider using sterile evacuated coagulation tubes rather than tubes containing potentially contaminated home-made anticoagulant.

SURVIVAL AND SHORT-TERM OUTCOME OF INBORN "MICRO$\dagger 539$ PREMIES". J.S. Gerdes, S. Abbasi, V.K. Bhutani, F.W. Med.and Pennsylvania Hospital, Dept.of Peds., Philadelphia The mortality and major morbidity of 104 consecutive micropremie". 1ive born deliveries (1982-1984) in an inborn perinatal center was examined by retrospective chart review. "Micropremies" are defined as AGA infants with BW $500-1000 \mathrm{gm}$ and $\leq 28$ weeks gestation.

$\begin{array}{lrrrrrl}\text { tion. } & 24 & 25 & 26 & 27 & 28 & 25-28 \\ \text { Wks. Gest. } & 7 & 19 & 25 & 31 & 22 & 97 \\ \mathrm{n} & 71 & 71 \\ \mathrm{x} \text { BW (gm) } & 651 & 735 & 740 & 860 & 910 & 814 \\ \text { Survival } & 0 \% & 39 \% & 58 \% & 83 \% & 76 \% & 67 \%\end{array}$
There was no difference between survivors (S) and non-survivors (NS) in PROM, C-section, or Apgar scores. There was a significant difference between $S$ and NS for pneumothorax ( $9 \%$ vs $28 \%$ ) and for mean maximum FIO $(.53$ vs 1.00$)$. Survival rates by sex and race: white females $61 \%$; white males $38 \%$; black females $90 \%$; black males $70 \%$. Morbidity rates among survivors: Sepsis $20 \%$; NEC $17 \%$; IVH $42 \%$ (Grade 3 or $4,11 \%$ ); PDA $50 \%$; ROP $64 \%$ (Grade $323 \%$, Grade $41 \%$; $\mathrm{BPD} 65 \%$; severe BPD requiring $\mathrm{O}_{2}>3$ mos. $18 \%$; apnea $69 \%$; seizures $11 \%$. Mean days on ventilator was 37 (range $0-103$ ), and average length of stay was 93 days (range 61-200), excluding 3 infants who were hospitalized for 6-18 months in chronic care facilities. One infant is blind from ROP; 2 had shunts for hydro cephalus; 1 required tracheostomy for subglottic stenosis. Conclusions: The acceptable prognosis for "micropremies" supports aggressive perinatal management as low as 25 weeks gestation. Race and sex are important determinants of outcome in these infants. \section{FACTORS IN THB POSSIBLE NOSOCOMIAL SPREAD OF
540 HARMOPHILUS MNLUENZAE TYPE b (HIB). Janet R.
Gilsdorf and Gerald Herring.
(Spon. by Robert P.} Kelch) C.s. Mott Children's Hospital, University of Michigan Medical Center, Ann Arbor, MI.

Serial nasopharyngeal (np) cultures for Hib were obtained from twenty-three children (ages 2 months to 9 years) with invasive Hib disease during systemic antibiotic therapy (ampicillin, chloramphenicol,
or both). During the first 12 hours of antibiotic therapy, 4 of 10 or both). During the first 12 hours of antibiotic therapy, 4 of 10
$(40 \%) \mathrm{np}$ cultures were positive; during the first 24 hours of therapy, $(40 \%) \mathrm{np}$ cultures were positive; during the first 24 hours of therapy,
6 of $25(24 \%)$ were positive. None of the 74 cultures obtained after 6 of $25(24 \%)$ were positive. None of the 74 cultures obtained after
25 hours of therapy (median $=5$ days) were positive for Hib. Four of six children who had received no antibiotics at the time of the initial np culture were culture positive and had moderate (21 to $100 \mathrm{cfu} /$ plate) or many ( $>100 \mathrm{cfu} /$ plate) Hib present. The positive cultures obtained more than three hours after the first dose of appropriate therapy had rare ( $<5$ cfu/plate) Hib present.

Reconstruction experiments to investigate the survival of Hib in the environment were performed using $10^{3}, 10^{5}$ or $10^{7}$ cfu Hib mixed with tracheal secretions and applied to various surfaces. Using $10^{3}$ efu, all surfaces tested had no Hib recovered beyond $15 \mathrm{~min}$. afte contamination. Using $10^{5}$ or $10^{7} \mathrm{cfu}$, Hib was recovered from stainless steel, plastic laminate countertop and plastic gloves for at least 120 min. and from paper towels up to 15 or $45 \mathrm{~min}$. after contamination. No Hib was isolated beyond $1 \mathrm{~min}$. from cotton sheets.

These results suggest that respiratory secretion precautions for patients hospitalized with invasive Hib disease should be maintained for 48 hours after initiation of adequate antimicrobial therapy to prevent possible nosocomial spread of this organism. 